\title{
Preparation and Comparison of Low Cost Media for Fungus Growth
}

\author{
Arvind Lal ${ }^{1}$, Febi John ${ }^{2}$, C. S. Senthamil Selvi ${ }^{* *}$ and M. Revathi ${ }^{1}$ \\ 'Department of Microbiology, Palanisamy College of Arts, Perundurai, Erode - 638052, Tamil Nadu, India; \\ cssenthamilselvi@gmail.com \\ 2Department of Biochemistry, Sree Sankara College, Kelady, Ernakulam - 683574, Kerala, India
}

\begin{abstract}
The cost of preparation of selective media for the fungus is costly. The preparation of media with low cost supplements can be efficiently used for the growth of fungus thereby reducing the cost of media preparation. So, we have selected four different low cost, locally and naturally available materials like Tender Coconut Water (TCW), milk, whey and toddy were selected for the media preparation. Three different fungi i.e, Aspergillus niger, Fusarium species and Mucor species were tested.
\end{abstract}

Keywords: Fungus, Milk, Tender Coconut Water (TCW), Toddy, Whey

\section{Introduction}

Microorganisms need nutrients, a source of energy and certain environmental conditions in order to grow and reproduce. In the environment, microbes adapt to the habitats most suitable for their needs while in the laboratory, these requirements must be met by a culture medium. So growth media are used for various purposes including the identification of unknown microorganisms, as well as the production of large quantities of microbial populations for commercial uses as in biotechnology. Numerous types of media are available commercially including some that may have added compounds that either enhance growth or suppress outgrowth of competing organisms. Complex media are rich in nutrients; they contain water soluble extracts of plant or animal tissue. Usually, sugar or glucose is added to serve as the main carbon and energy source. The combination of extracts and sugar creates a medium which is rich in minerals and organic nutrients, but since the exact composition is unknown the medium is called complex. Selection of preferred media is based on how it affects the microorganism's growth and other physiological functions and the purpose of research. The present study was to develop low cost media for fungi growth and compare low cost medium with normal SDA medium.

\section{Materials and Methods}

\subsection{Preparation of Low Cost Media using Coconut, Milk, Whey and Toddy \\ 2.1.1 Preparation of Tender Coconut Water (TCW) Agar Media}

About $50 \mathrm{ml}$ of fresh Tender Coconut Water was filtered by membrane filter of pore size $0.45 \mu \mathrm{m}$. To 50 
$\mathrm{ml}$ of sterile water, $2 \mathrm{~g}$ agar was added in a conical flask and autoclaved at $121^{\circ} \mathrm{C}$. Then added $50 \mathrm{ml}$ of sterilized Tender Coconut Water to this and mixed well. Then the TCW media was poured into the sterilized petri dish to about $20 \mathrm{~mm}$ thickness and allowed to solidify.

\subsubsection{Preparation of Milk Agar Media}

About $100 \mathrm{ml}$ of sterile water was taken in a conical flask and added $2 \mathrm{~g}$ agar to it and autoclaved at $121^{\circ} \mathrm{C}$. Then added $1 \mathrm{ml}$ of pasteurized milk to it and mixed well. The prepared media was poured into the sterilized petri dish to $20 \mathrm{~mm}$ thickness and solidified.

\subsubsection{Preparation of Whey Agar Media}

In a conical flask $100 \mathrm{ml}$ of whey was taken and $2 \mathrm{~g}$ of agar was added and autoclaved at $121^{\circ} \mathrm{C}$. The media was poured into the sterilized petri dish with $20 \mathrm{~mm}$ thickness. Then it is allowed to solidify.

\subsubsection{Preparation of Toddy Agar Media}

The fresh toddy was filtered by membrane filter of pore size $0.45 \mu \mathrm{m}$. About $50 \mathrm{ml}$ of sterile water was added to the conical flask and added $2 \mathrm{~g}$ agar to it. This was then autoclaved at $121^{\circ} \mathrm{C}$ to which $50 \mathrm{ml}$ of sterilized toddy was added and mixed well. Then the media was poured in to the sterilized petri dish with $20 \mathrm{~mm}$ thickness. Then allow it to solidify.

\subsubsection{Preparation of SDA}

$1 \mathrm{~g}$ of peptone and $4 \mathrm{~g}$ of dextrose was added to a 100 $\mathrm{ml}$ of distilled water. $\mathrm{pH}$ of the media was adjusted to 5.6 and $2 \mathrm{~g}$ agar was added to it. The medium was autoclaved at $121^{\circ} \mathrm{C}$ for 1 hour. The media was poured to petri dish and allowed to solidify.

\section{Inoculation of Fungus}

The fungal species like Aspergillus niger, Fusarium sp., Mucor sp. were used for inoculation in newly prepared medium like TCW agar media, milk agar media, whey agar media, toddy agar media. Stab culture is the technique used for fungal inoculation.

\section{Lactophenol Cotton Blue Mounting of Fungi}

Place a drop of lactophenol cotton blue on a clean glass slide. Transfer a small tuft of the each fungus preferably with spores and spore bearing structures in to the drop using a flamed and cooled needle. Gently tease the material using the two mounting needle. Mix gently the stain with the mold structures Place a cover slip over the preparation taking care to avoid trapping air bubbles in the stain. Remove excess of stain from around the cover slip with a blotting paper. Examine the slide first under low power objective (10x) and high power objective (45x).

\section{Result and Discussion}

In our study, three different fungi i.e. Aspergillus niger, Fusarium sp. and Mucor sp. were tested in all the four prepared low cost media and in SDA media. The growth of all the four fungus was seen in TCW, milk, whey and toddy media and also in SDA media (Table 1).

Aspergillus niger was seen to grow faster in TCW media when compared to milk, whey and toddy and also when compared to SDA. The full growth of Aspergillus niger was seen on the $4^{\text {th }}$ day in the SDA, milk, whey and toddy media whereas in the TCW media growth was seen from the $2^{\text {nd }}$ day onwards (Plate 1$)$. The full growth of Fusarium sp. and Mucor sp. (Plates 2 and 3) were seen on the $8^{\text {th }}$ day in SDA medium and $4^{\text {th }}$ day in milk, whey and toddy media whereas in the TCW media growth was seen from the $2^{\text {nd }}$ day onwards. Nowadays potato dextrose medium is also used for fungal isolation.

Qiyun and Liang, (2004) $)^{1}$ studied the use of potato processing waste as a fermentation substrate for the production of Single Cell Proteins (SCP) for use in supplementation of animal feeds. Composition before and after fermentation was determined and this showed that the crude protein contents were 13.4, 18.53 and $22.16 \%$, for the raw, steamed and solid-state treatments, respectively. As the current research shows, the protein of raw potato wastes has been usable much more than steamed or solid-state wastes for microorganisms' growth. 
Table 1. Number of days taken for full fungal growth appearance in petri plates

\begin{tabular}{|c|c|c|c|c|c|c|}
\hline S. No & Name of fungi & SDA & Toddy & Tender Coconut Water & Milk & Whey \\
\hline 1 & Aspergillus niger & 3 & 4 & 2 & 4 & 4 \\
\hline 2 & Fusarium sp. & 8 & 4 & 4 & 4 & 4 \\
\hline 3 & Mucor sp. & 8 & 4 & 4 & 4 & 4 \\
\hline
\end{tabular}

Plate 1. Growth of Aspergillus niger on low cost media compared with commercially available Sabouraud Dextrose Agar (SDA) media.




Plate 2. Growth of Fusarium sp. on low cost media compared with commercially available Sabouraud Dextrose Agar (SDA) media.

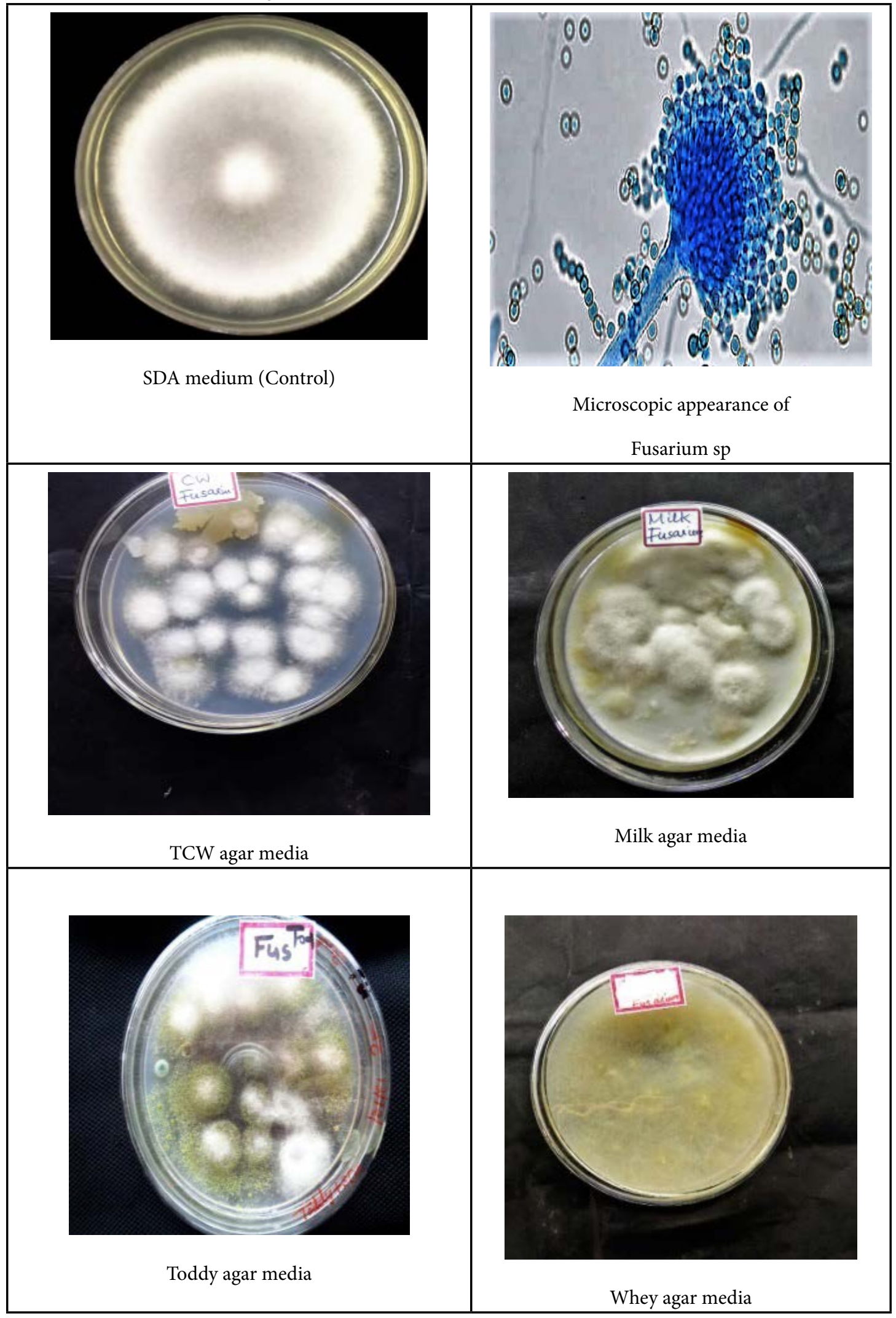


Plate 3. Growth of Mucor sp. on low cost media compared with commercially available Sabouraud Dextrose Agar media.

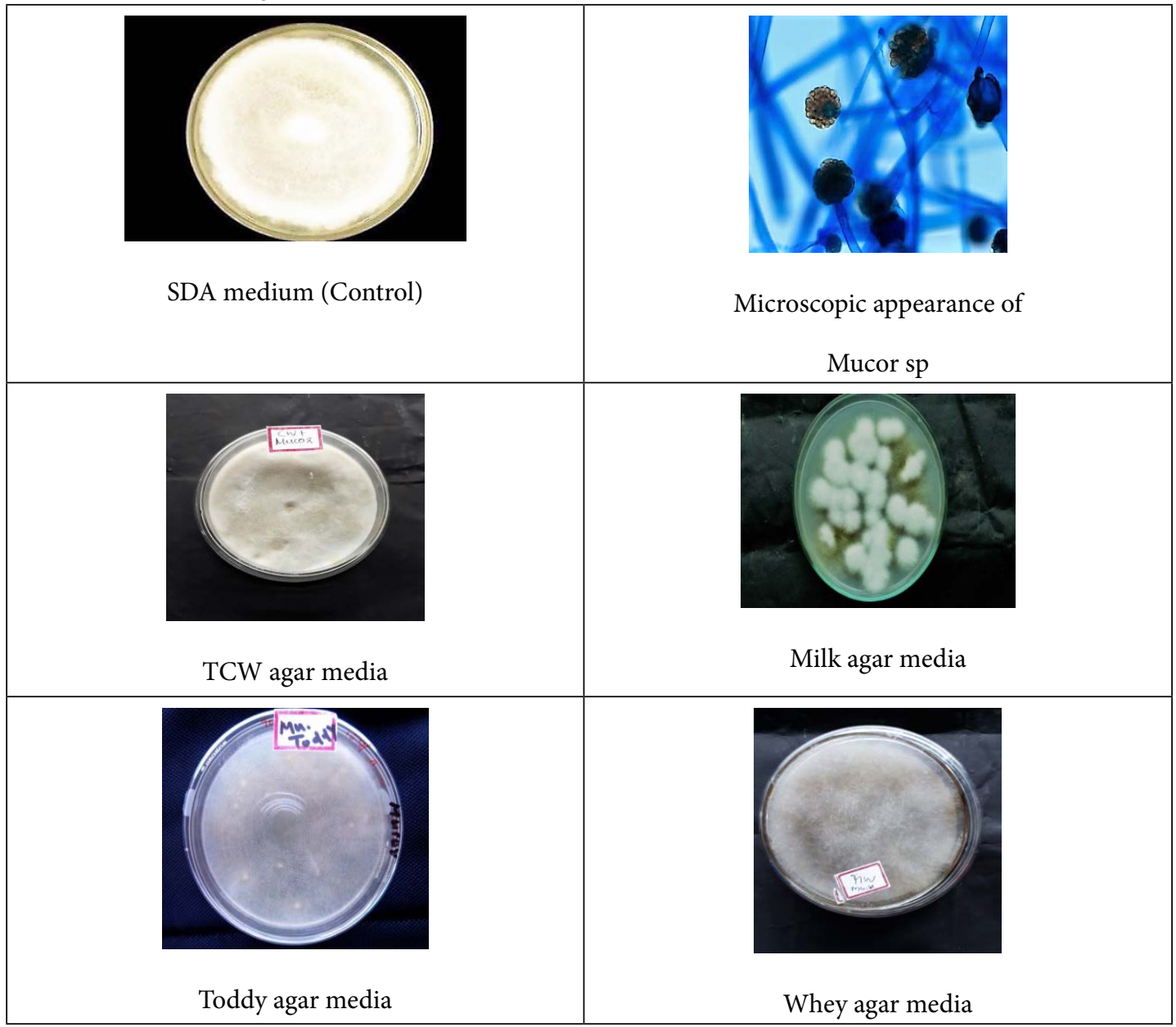

Vazquez et al., (2004) $)^{2}$ formulated new marine medium and evaluated for their effectiveness for promoting growth of different bacteria.

\section{Conclusion}

The study of microorganism requires the preparation of media. Usually costly synthetic media are available and also the costs of preparation of media are also costly. The present study succeeded in using locally available, low cost materials in preparing media. Further studies on the use of TCW as a media as well as broth may help the preparation of media in a less costly way.

\section{Reference}

1. Qiyun SH, Liang QI. Study on the production of SCP feed from potato mash residue. Cereal Feed-Ind. 200; 9:32-33.

2. Vazquez JA, Gonzalez MP, Murado MA. New marine medium: Use of different fish peptones and comparative study of the growth of selected species of marine bacteria. Enzyme Microb Technol. 2004; 35(5):385-92. https://doi. org/10.1016/S0141-0229(04)00180-2 